\title{
A obrigação dos entes federados ao fornecimento de medicamentos experimentais
}

\author{
Vanessa Desirée Gallas ${ }^{1}$ \\ Letícia Lassen Petersen ${ }^{2}$
}

\section{RESUMO}

$\mathrm{O}$ artigo analisa a obrigatoriedade do fornecimento e financiamento público de medicamentos experimentais, à luz da discussão do direito fundamental à saúde, no espaço territorial do Rio Grande do Sul. A delimitação temática consiste na análise das decisões judiciais do Tribunal de Justiça do Estado do Rio Grande do Sul (TJ/RS), no ano de 2012, acerca da obrigatoriedade dos entes federados em fornecer medicamentos considerados experimentais. O problema proposto concentra-se em observar qual a interpretação dada pelo TJ/RS, em relação à obrigatoriedade dos entes federados fornecer medicamentos de caráter experimental. A discussão proposta ultrapassa os limites de atuação pública quanto à oferta de prestações de bens públicos na esfera da saúde coletiva, em razão de que as decisões analisadas poderiam extrapolar a própria regulamentação do acesso e disponibilidade de tratamentos/ medicamentos no cenário econômico. Além disso, há que se ponderar a dimensão da responsabilidade civil frente aos tratamentos que serão disponibilizados à população pelo Estado. Notadamente em relação ao fornecimento de tratamentos experimentais, que implica a submissão de seres humanos a experiências científicas, esta sempre deverá ocorrer de forma restrita, acompanhada por pesquisador responsável, nos termos do Código de Ética Médica e regulamentações de pesquisa em humanos feita pelo Ministério da Saúde. Nesta seara, percebe-se que a existência de decisões judiciais concessivas poderá apresentar grande equívoco ao compelir os entes federados ao fornecimento deste tipo de medicamento, pautando-se no argumento de proteção ao direito à vida, quando em verdade, acabariam por promover e financiar pesquisas da própria indústria farmacêutica, e que mais tarde, reverteriam em patentes comerciais para as mesmas.

Palavras-chave: fornecimento público - medicamento experimental - judicialização

\section{INTRODUÇÃO}

A interpretação do direito à saúde enquanto um princípio absoluto do direito de dignidade da pessoa humana, pelo Tribunal de Justiça do Rio Grande do Sul (TJ/RS), tem proporcionado a tomada de decisões em massa, partindo da premissa que o direito individual à saúde é expressão de garantia constitucional insculpida no art. 196 da CF/88. Essa postura interpretativa do TJ/RS, proporciona um descaminho à toda regulação do mercado de medicamentos, qual seja, impõe o fornecimento público de medicamentos que ainda não

\footnotetext{
${ }^{1}$ Fundação Educacional Machado de Assis (FEMA)

${ }^{2}$ Doutora. Universidade de Santa Cruz do Sul (UNISC), Fundação Educacional Machado de Assis (FEMA) e Faculdade América Latina (FAL). Email: letipetersen@yahoo.com.br
} 
foram reconhecidos pela ANVISA, nos critérios de segurança e eficácia para o quadro diagnóstico ao qual está sendo prescrito.

Para além da questão de insegurança da prescrição, que atinge a saúde individual, a problemática ainda traz como questão de fundo, o financiamento público da pesquisa industrial e da obtenção da patente de invenção. Percebe-se que os resultados da pesquisa desenvolvida, reverterão em lucro para a indústria farmacêutica, em razão do depósito de patentes e consequente monopólio de produção ao longo da vigência deste instituto jurídico.

Esta pesquisa se dedicará a tabulação das decisões do TJ/RS, relativas ao ano de 2012, que deferiram o fornecimento de medicamentos experimentais, interpretando-o como parte do direito à saúde. Para apresentá-las ao leitor, parte-se da análise dos argumentos que dão suporte às decisões judiciais proferidas pelo TJ/RS, deferindo o financiamento público de tratamentos experimentais ao longo do ano de 2012, em que o polo passivo da demanda é composto por entes federados (estado ou município). A presente verificação se dará mediante a realização de pesquisa bibliográfica e documental, realizada por meio de apuração quantitativa de decisões definitivas no TJ/RS ao longo do ano de 2012 e análise qualitativa dos argumentos que fundamentam as decisões apuradas.

Dessa forma, caso a postura adotada pelo Poder Judiciário, venha determinar o financiamento público de medicamentos experimentais, demonstraria o desconhecimento e uma possível distonia deste Poder, em relação às regulamentações realizadas pelo Poder Executivo, o que evidenciaria possível desconhecimento acerca dos riscos que estas prescrições poderiam implicar para a saúde individual, em nome da absolutização do conceito de acesso a tratamentos individuais em saúde pública.

Esta postura faria com que os entes públicos fossem compelidos: (1) a fornecer medicamentos sem aprovação pela ANVISA para o tratamento dos quadros diagnósticos atestados pelos profissionais da medicina, colocando em risco a vida dos sujeitos que a estes tratamentos se submetem; (2) a pagar preços desarrazoados para alcançar tais substâncias, não seguindo os princípios de racionalidade dos gastos públicos, que fundamentam o direito administrativo.

O primeiro ponto da pesquisa dedica-se ao enfrentamento teórico conceitual da previsão constitucional do direito à saúde e seu caráter programático, esclarecendo a peculiaridade de bem público que o fornecimento de tratamentos de saúde assume na relação Estado e sociedade. Procurar-se-á apresentar um panorama geral da regulação do mercado de medicamentos - maior expressão tecnológica em saúde, onde se encontra afirmada a 
problemática experimental e do risco, objeto da pesquisa - bem como a estruturação do fornecimento de medicamentos pelos entes públicos.

O segundo ponto, ainda de caráter conceitual, fruto de pesquisa documental e bibliográfica, se dedica a dar continuidade à abordagem do fornecimento público de medicamentos e a realização de pesquisa em humanos, apresentando a regulamentação pública deste tipo peculiar de pesquisa. Para finalizar, o artigo se dedica ao enfrentamento do possível descaminho ao recorte da Política Nacional de Assistência Farmacêutica, realizado pelo Poder Judiciário ao admitir o fornecimento de medicamento experimental em nome do direito à saúde. Busca-se sistematizar quais argumentos referidos pelas Câmaras do TJ/RS que fundamentam a obrigatoriedade dos entes federados ao fornecimento de medicamentos que ainda se encontram em caráter experimental, ou seja, de eficácia não comprovada ou duvidosa, apurando as sintonias e distonias verificadas nas decisões do Poder Judiciário frente à regulamentação da política pública que estrutura o fornecimento do bem público medicamentos.

A partir deste diálogo teórico e tabulação das decisões jurisprudenciais que enfrentaram a matéria, é possível apresentar os argumentos utilizados tanto em relação ao fornecimento deste tipo de medicamento, quanto em relação aos argumentos que deram suporte à decisões negativas de fornecimento.

\section{PREVISÃo CONSTITUCIONAL dO DIREITO À SAÚde E SEU CARÁter PROGRAMÁTICO.}

O direito à saúde encontra-se previsto na Constituição Federal de 1988 (CF/88), em seu artigo $196^{3}$, o qual atribui ao Estado a responsabilidade de promoção deste direito fundamental. Depreende-se da mencionada previsão, que a vontade do legislador para concretização do direito em questão, esta vinculada a implementação de políticas públicas sociais e econômicas que visem à redução do risco e da doença e de outros agravos -, por parte do Estado, a fim assegurar a efetiva promoção e proteção do direito à saúde. Esta circunstância coloca o direito à saúde na condição de bem público em toda sua extensão, como pontua Petersen (2014, p. 15).

\footnotetext{
3 Art.196. A saúde é direito de todos e dever do Estado, garantindo, mediante políticas sociais e econômicas que visem à redução do risco de doença e de outros agravos e ao acesso universal igualitário às ações e serviços para sua promoção, proteção e recuperação (BRASIL, 1988).
} 
Dessa forma, o Estado se organizou por meio de diversas ações políticas de gestão, promoção de estímulos, regulamentação direta e restrições para organizar a promoção deste direito, conforme é sistematizado por Petersen:

A promoção do direito social à saúde se reveste de múltiplas ações governamentais para seu alcance: que envolvem fiscalização das prestações na seara da saúde, regulação econômica tanto dos serviços quanto dos insumos comercializados em nome de sua promoção, especificamente em relação ao que é oferecido à população, há que se destacar o planejamento (de oferta, de organização, gestão, recursos), descentralização da gestão entre os entes federados com a consequente divisão de responsabilidades, a regulação da atuação dos atores públicos, a presença de corpo técnico qualificado, a formação de espaços decisórios de participação social até ver efetivado o acesso por parte do cidadão, de uma gama de ofertas seguras, que protejam o preciso bem da vida, enquanto destinatário final deste conjunto de medidas. (PETERSEN, 2014, p. 37).

O SUS, como popularmente é conhecido, é o maior programa público de proteção à saúde, tanto em razão do número de habitantes que alcança (eis que possui caráter universal), como em razão da extensão territorial que necessita se fazer presente. Desta forma, embora as diretrizes gerais sejam definidas pela União, sua organização prevê competências descentralizadas, que refletem diretamente na gestão para possibilitar, o mais amplo acesso à saúde pela população em geral. Conforme destaca Moraes, o Estado planejou o Sistema Único de Saúde, e após a sua criação, passou a instituir políticas para executar ações voltadas para a saúde, bem como fiscalizar procedimentos e produtos, dentre outras estabelecidas em lei (MORAES, 2010, p.830).

Neste sentido contribui Mello, quando menciona que a $\mathrm{CF} / 88$, detém uma força jurídica vinculante, ou seja, “o regramento constitucional é acima de tudo, um conjunto de dispositivos que estabelecem comportamentos obrigatórios para o Estado e para os indivíduos" (MELLO, 2011, p.12). No mesmo sentido, Kelbert analisa o caráter analisa o caráter programático da norma que acaba por imputar ao Estado o cumprimento desta programação,

Assim, o caráter programático atribuído às normas que preveem direitos sociais vai perdendo força, pois a dimensão objetiva implica a adoção de medidas efetivas voltadas ao cumprimento das escolhas constitucionais.

Embora a dimensão programática possa ser relativizada no que concerne à dimensão prestacional dos direitos sociais, ela existe no sentido de imposição de deveres e tarefas para o Estado, que devem ser vinculados por meio de políticas públicas [...] (KELBERT, 2011, p.53).

A normativa, em seu aspecto puramente garantista, não tem eficácia imediata ${ }^{4}$, pois necessita de normas que institucionalizem as ações que serão tomadas pelo Estado para

\footnotetext{
${ }^{4}$ José Afonso da Silva contempla a seguinte classificação quanto à eficácia das normas constitucionais: "a) normas constitucionais de eficácia plena, que seriam aquelas de imediata aplicação; b) norma constitucional de eficácia contida prevê meios ou conceitos que permitem manter sua eficácia contida em certos limites, dadas
} 
cumprir com o desejo anunciado na norma constitucional. Significa que a existência da norma por si só, não efetiva o cumprimento do direito ali previsto: de forma ilimitada, sem que se observe a racionalidade pública estruturada para este fim. Merece destaque, desde já, o fato do sistema público de saúde no Brasil ser fruto de ampla discussão técnica, pautado por conceitos amplamente acolhidos pela medicina ortodoxa, fruto de pesquisa que demonstram evidências médicas para abarcar a universalidade e a construção de um conjunto de ações que possam viabilizar a autonomia dos cidadãos, conforme já fora pontuado por Petersen,

A $\mathrm{CF} / 88$ propõe uma ruptura em relação à velha concepção de direito à saúde, enquanto um benefício de acesso restrito. Ela oferece abertura política para a construção de uma nova perspectiva na agenda de governo, comprometida com a oferta universal de ações curativas do procedimento médico, compreendendo sua garantia como resultado de uma série de ações políticas (políticas públicas) capazes de modificar as condições de existência e criação de autonomia dos cidadãos. (PETERSEN, 2014, p. 69).

Em relação à força normativa das disposições constitucionais, cumpre referir a seguinte definição criada pelo doutrinador Hesse:

A constituição adquire força normativa na medida em que logra realizar essa pretensão de eficácia. Essa constatação leva a uma outra indagação, concernente às possibilidades e aos limites de sua realização no contexto amplo de interdependência no qual esta pretensão de eficácia encontra-se inserida (HESSE, 1991, p.16).

Verifica-se a existência de uma relação de interdependência que se dá em razão da eficácia obtida pelo cumprimento da normativa, bem como uma mensuração acerca das possíveis limitações, das quais esta norma estará exposta para que possa ser plenamente satisfeita. A determinação constitucional concernente ao direito à saúde, para ser eficaz deve ser possível. De forma a enfatizar o caráter programático, a garantia do direito a prestação de ações e serviços em saúde, financiado pelo poder público, é retomada com o mesmo intuito no artigo $198^{5}$ do mesmo diploma legal, constituindo-se o sistema de saúde por meio de uma estrutura hierarquizada e descentralizada. O objetivo desta estrutura é de garantir o atendimento em saúde em toda extensão territorial do Brasil.

Da incipiente estrutura apresentada pelo texto constitucional, retoma-se a programação por meio de regulamentação infraconstitucional, a fim de retirar o seu caráter

certas circunstâncias; c) normas constitucionais de eficácia limitada ou reduzida não produzem, com a simples entrada em vigor, todos os seus efeitos essenciais [...]” (SILVA, 2008, P.82).

5 Art. 198. As ações e serviços públicos de saúde integram uma rede regionalizada e hierarquizada e constituem um sistema único, organizado de acordo com as seguintes diretrizes:

I - descentralização, com direção única em cada esfera de governo;

II - atendimento integral, com prioridade para as atividades preventivas, sem prejuízo dos serviços assistenciais; III - participação da comunidade (Constituição Federal de1988). 
genérico, e, por conseguinte, possibilitar a sua aplicabilidade de forma mais eficaz. Neste contexto trata Mello:

[...] outros versículos constitucionais, em decorrência de sua dicção, dependem de normação infraconstitucional para despenderem a plenitude dos efeitos a que se destinam e que neles se encontram virtualmente abrigados, isto é in fieri. Também eles, de imediato, deflagram efeitos, porém de menor densidade que os anteriores. Com efeito, não outorgam, por si mesmos, o desfrute positivo de um benefício, nem permitem exigir que este venha a ser juridicamente composto e deferido (MELLO, 2009, p.15).

Hesse afirma que a Constituição, de modo isolado, não é eficaz na garantia de direitos por ela instituídos, razão pela qual se cria uma relação de interdependência com uma norma infraconstitucional, a fim de possibilitar uma eficácia plena para o cumprimento daquela normativa.

Embora a Constituição não possa, por si só, realizar nada, ela pode impor tarefas. A Constituição transforma-se em força ativa se essas tarefas forem efetivamente realizadas, se existir a disposição de orientar a própria conduta segundo a ordem nela estabelecida [...] (HENSSE, 1991, p.19).

A criação de legislação específica se mostra determinante para o real cumprimento das garantias constantes na $\mathrm{CF} / 88$, pois, através desta, criam-se mecanismos que possibilitam o cumprimento daquelas disposições. Hermann também entende que a determinação trazida pela magna carta, no sentido de resguardar o direito a saúde, mostra-se insuficiente e inefetiva, haja vista que:

Os direitos fundamentais tomam cada vez mais o caráter de promessas e explicações de programas, ao mesmo tempo em que mais e mais se valoriza o seu conteúdo jurídico. As seções de direitos fundamentais de inúmeras Constituições formigam de promessas, cujo cumprimento os Estados jamais pensaram. São absolutamente supérfluas, sem valor, e nada tem que fazer na Constituição [...] (HERMANN, 1957, p.79, apud FERREIRA, 2002, p.541).

O autor pontua que, em muitos países, a ineficácia da normativa se dá em razão da impossibilidade de execução da mesma, pois não há dispositivo que permita a concretização de tal direito, bem como não há como se verificar a extensão de possíveis consequências em relação ao próprio direito instituído. No mesmo sentido se dá o entendimento de Webber, ao afirmar que o direito à saúde, posto pela $\mathrm{CF} / 88$, é ineficiente por tratar-se de uma garantia vaga, conforme segue:

[...] tem-se que, diante do caráter vago que a expressão Direito à saúde apresenta, não é capaz de dizer, de maneira clara e sem objeções, no que consiste o Direito a Saúde. Ou melhor, quais os limites da expressão a saúde é direito de todos, diante da sua amplitude, indeterminação de significado e vagueza semântica. Como se pode observar, a norma que garante o acesso à saúde no Brasil foi elaborada de forma vaga (WEBBER, 2013, p.112). 
Essa abrangência da previsão constitucional foi suprida pelos limites institucionais do SUS, Lei n. ${ }^{\circ}$ 8.080/1990, que se dedicou a dar início às ações do Estado com vistas à efetivação do direito à saúde, que foram assegurados em 1988 e carência de estruturação. Embora se presuma que instâncias julgadoras tenham conhecimento de todo arcabouço normativo pátrio, verifica-se na prática que em alguns Tribunais, como o TJ/RS, o ativismo judicial tem levado em consideração apenas os dispositivos constitucionais, ao enfrentar litígios envolvendo direitos sociais, interpretando-os de maneira ampliativa. Essa postura, expressa na interpretação ampliativa da norma, cria um espaço de relativização, do bem jurídico tutelado pela $\mathrm{CF} / 88$, que acaba por extrapolar os limites da oferta do bem público, a qual estaria submetida.

Segundo Salazar e Grou, a fim de suprir os dispositivos constitucionais, referentes ao direito à saúde, cria-se a Lei 8.080/90 que passará a dispor acerca de condições para a promoção, recuperação, organização e funcionamento dos serviços referentes à saúde, nos seguintes termos:

\begin{abstract}
Além das normas constitucionais referidas, que não deixam dúvidas acerca da aplicabilidade imediata e força vinculante do direito à saúde, a legislação infraconstitucional reforça e especifica o direito à assistência à saúde, sobretudo a Lei 8080/90, Lei Orgânica da Saúde. As normas infraconstitucionais também cuidam da organização do Sistema Único de Saúde, dividindo atribuições entre as três esferas de governo gestoras do SUS [...] (SALAZAR, e GROU, 2009, p.44).
\end{abstract}

Desta forma, a previsão constante no artigo $5^{\circ}$ e incisos da Lei n. ${ }^{\circ} 8.080 / 90$, tem por consequência a identificação dos objetivos de que trata esta legislação. Já no inciso II pode-se depreender a criação de políticas direcionadas à saúde, possibilitando, a partir desta regulamentação, o cumprimento do que consta no artigo $2^{\circ}, \S 1^{\circ}$, o qual atribui ao Estado a garantia ao acesso à saúde, instituídos pela $\mathrm{CF} / 88$. Neste sentido, cumpre salientar a classificação de competência entre os entes federados para a tutela da saúde, atribuída por Salazar e Grou:

Cuidar da Saúde é competência material comum da União, dos Estados, do Distrito Federal e dos Municípios, conforme o artigo 23, inciso II, da Constituição Federal. Na mesma acepção, o artigo 30, ao tratar da competência dos Municípios, estabelece que a prestação dos serviços de atendimento à saúde da população deve ser feita com a cooperação técnica e financeira da União e do Estado (inciso VII). Desse modo, atuar em saúde é tarefa que cabe a todos os entes públicos, sendo aos Municípios conferida a função de principal prestador dos serviços públicos de atenção à saúde (SALAZAR; GROU, 2009, p.19). 
A competência material de prestações de saúde recai aos entes federados, contudo há uma forte tendência de que este direito seja satisfeito, principalmente, na esfera Municipal. Verifica-se, por essa razão, que a legislação infraconstitucional acaba por suprir as lacunas regulamentadoras do direito à saúde garantida pela $\mathrm{CF} / 88$, nesse sentido, igualmente cabe referir a Lei n. ${ }^{\circ}$ 8.142/90 que trata da participação da sociedade na gestão do SUS.

A normativa constitucional, no que tange ao direito à saúde, não deve ser observada de forma isolada, mas sim de forma conjunta com a legislação infraconstitucional específica e demais regulamentações que definem e especificam tecnicamente a forma de aplicabilidade daquele direito genericamente previsto. Cabe salientar que o direito a saúde é caracterizado como um direito fundamental estabelecido pela própria $\mathrm{CF} / 88$, e considerado como uma garantia da dignidade da pessoa nos termos do que dispõe o art. $1^{\circ}$, inciso III, da CF/88 (SALAZAR; GROU, 2009, p.14) e por este motivo carece, ainda mais, de uma regulamentação técnica médica.

No que tange ao direito fundamental da saúde, a doutrinadora Lins remonta duas perspectivas de análise para a referida garantia, conforme se verifica

Em síntese, o direito fundamental à saúde pode ser reconduzido à noção de direito negativo (de defesa) ou direito positivo (de prestações). Como direito negativo assegura a proteção da saúde individual e coletiva contra a interferência indevida pelo Estado ou por particulares. Na condição de Direito positivo, em sentido amplo, assegura o dever da prática de atos que assegurem a proteção do direito à saúde [...] (LINS, 2012, p.79/80).

Sendo assim, a garantia do direito à saúde, posto pelo Estado configuraria um direito negativo, na medida em que não é assegurado o dever da prática de atos que tem por fim assegurar o direito à saúde.

\subsection{MEDICAMENTOS E SUA AUTORIZAÇÃO PARA COMERCIALIZAÇÃO NO BRASIL: A ATUAÇÃO DA ANVISA.}

A primeira forma política de intervenção pública em saúde é, sem dúvida, o controle dos bens de consumo postos para circulação no mercado de consumo. Assim, a vigilância sanitária dos medicamentos, alimentos, herbicidas, inseticidas, entre outros, realizada pela ANVISA, é de fundamental importância para evitar que produtos sem segurança, sem eficácia, com potencial risco para a população, sejam consumidos (CONASS).

Neste sentido entende o presidente do CONASS quando aponta que a vigilância sanitária é tida como uma forma de regulamentação da assistência à saúde, conforme segue: 
As ações da regulação da atenção à saúde compreendem a contratação, a regulação assistencial, a avaliação da Atenção à Saúde, a auditoria assistencial e as regulamentações da Vigilância Epidemiológica e Sanitária (CONASS, 2013).

O setor de medicamentos, na proposta desta análise, é o que merece maior atenção, pois a fim de regulamentar a comercialização de medicamentos no Brasil, houve a criação de normativas de vigilância sanitária conforme dispõe o artigo $3^{\circ}$ da Lei n. ${ }^{\circ}$ 9.782/99:

Art. $3^{\underline{0}}$ Fica criada a Agência Nacional de Vigilância Sanitária - ANVISA, autarquia sob regime especial, vinculada ao Ministério da Saúde, com sede e foro no Distrito Federal, prazo de duração indeterminado e atuação em todo território nacional (BRASIL, 1.999).

Para que determinado medicamento obtenha autorização para comercialização e circulação dentro do território brasileiro, deve-se atentar as normas estabelecidas pela Anvisa, uma agência reguladora, a qual o Estado incumbiu a fiscalização dos insumos relacionados à saúde. A finalidade desta agência reguladora está sistematizada no artigo $6^{\circ}$ da Lei n. ${ }^{\circ} 9.782$ de 1999:

Art. 6o- A Agência terá por finalidade institucional promover a proteção da saúde da população, por intermédio do controle sanitário da produção e da comercialização de produtos e serviços submetidos à vigilância sanitária, inclusive dos ambientes, dos processos, dos insumos e das tecnologias a eles relacionados, bem como o controle de portos, aeroportos e de fronteiras (BRASIL, 1.999).

Verifica-se que incumbe à Anvisa promover a proteção do consumidor em relação a todos os insumos relacionados à saúde, por meio de um controle de produção e comercialização, objetivando a proteção de toda uma população por eventuais riscos a saúde. Ademais, a doutrinadora Webber entende que a criação da Anvisa só veio a contribuir para o melhor funcionamento do sistema de saúde implantado no Brasil, neste sentido:

\footnotetext{
A Anvisa foi criada com a finalidade institucional de ampliar a promoção da saúde da população, por meio do controle sanitário da produção e comercialização de produtos e serviços submetidos à vigilância sanitária, incluindo-se os ambientes, o processo dos insumos e das tecnologias a eles relacionados e, ainda, o controle de portos, aeroportos e fronteiras (WEBBE, apud MARTINS, 2013, p.123).
}

A Anvisa é uma organização complexa que passou a exercer controle do fornecimento de medicamentos e produtos que devem ser cuidadosamente avaliados sob o crivo da vigilância sanitária, representando a intervenção estatal na economia que envolve 
este setor. Salienta-se, que os membros integrantes da Anvisa são extremamente qualificados para exercer o controle de qualidade de todo e qualquer insumo produzido ou que obtenha ingresso no país, em razão da formação técnica exigida para integrar a referida agência.

Cabe destacar, que só esta agência reguladora detém capacidade de avaliação para atestar que determinado fármaco pode ser, ou não disponibilizado no mercado para o consumo. Ela detém corpo técnico de profissionais que avaliam os produtos e exige dos fabricantes a demonstração de sua fórmula, bem como testes que envolvem demonstração de pesquisas quanto a segurança do produto, seu impacto na saúde em geral. Cumpridas as exigências da agência reguladora, e demonstrada a segurança do produto, ocorre a autorização para sua comercialização.

Neste sentido, o Conass, preocupado com o jogo de interesses que circunda o mercado de medicamentos e utensílios tecnológicos, faz um alerta quanto à confiabilidade que passamos a atribuir para as novas tecnologias, conforme segue:

O avanço tecnológico, muitas vezes erroneamente entendido como sinônimo de melhor qualidade da assistência à saúde, dá-se de forma muito acelerada e de maneira cumulativa, posto que nem sempre uma nova tecnologia substitui totalmente a anterior; antes, aperfeiçoa-a, aumentando sua sensibilidade e o grau de confiabilidade de seus resultados. (CONAS, 2013, p.29).

A Anvisa vem estabelecendo critérios para melhor avaliar os tipos de medicamentos que estão aptos a serem comercializados, sendo um destes parâmetros a verificação da qualidade dos fármacos, a qual se procede da seguinte forma:

\footnotetext{
A inspeção nas linhas de produção de medicamentos é um meio para comprovar seu funcionamento u funcionamento em acordo com os padrões que garantem a qualidade dos produtos. Na inspeção, a linha de produção deve estar condizente com a descrição detalhada do processo de produção e com as metodologias de controle de qualidade nas diferentes etapas (ANVISA, 2004).
}

Desta feita, percebe-se a existência de um controle rígido exercido pela agência nacional de vigilância sanitária acerca da eficácia de determinado medicamento. A autorização para comercialização deste tipo de insumo no território brasileiro pode ser obtidas, quando observado as disposições constantes nas resoluções criadas pelo CMED, que é o órgão responsável. Neste sentido cumpre mencionar a definição dada pela doutrinadora Webber, no que tange a relevância das atividades desenvolvidas pela Anvisa 
Assim, além do importante papel que a Anvisa desempenha enquanto organização que decide, entre outras coisas, sobre a aprovação ou não de um medicamento ou tratamento, ela tem um papel fundamental no acoplamento entre o Sistema do Direito e o Sistema da Saúde (WEBBE, 2013, p.126).

Igualmente, pode se verificar que o controle exercido, acaba por configurar uma atividade típica de Estado que é o exercício do poder de polícia ${ }^{6}$, de modo a fiscalizar as diretrizes que envolvem o fornecimento de medicamentos (FRAZÃO, 2002). O acesso a medicamentos é um setor que merece acompanhamento público, em razão da presença de seu uso de forma significativa junto às famílias brasileiras. Estudo realizado pelo Instituto Brasileiro de Geografia e Estatística (IBGE), mediante coleta de dados entre os períodos de 2002-2003 e 2008-2009, restou evidenciado que os gastos despendidos pelas famílias brasileiras para aquisição de medicamentos variam em razão de sua posição socioeconômica. Os referidos estudos apontam que o medicamento é o insumo principal, no que tange aos gastos em saúde pelas famílias, concluindo que "a alta desigualdade na distribuição de renda, que ainda prevalece na sociedade brasileira, se manifesta da mesma forma na alta desigualdade do gasto das famílias com medicamentos" (GARCIA; MAGALHÃES et al, 2013).

Perceba que a complexidade que envolve as dimensões a serem enfrentadas pelo Estado em nome da política de saúde abarca a própria regulamentação da autorização de venda pela Anvisa e fixação de preços médios ao consumidor. Salienta-se que a Anvisa lidera outras iniciativas como incentivos à indústria farmacêutica nacional, ou mesmo à produção pública de medicamentos que afetam tanto o acesso aos medicamentos, como impõem um controle ou concorrência para minoração de preços:

As políticas públicas devem buscar incentivar a concorrência ou diminuir os preços dos bens de saúde mesmo quando existe uma clara política de distribuição porque, neste caso, o financiamento destes gastos é realizado pelas receitas do governo [...] (BAYMA; KASZNAR, 2003, p.194).

A Anvisa representa a primeira forma de atuação pública para o acesso racional a medicamentos pela população, comprometida com a fiscalização da droga, obrigatoriamente a ela submetida, bem como a publicidade de sua bula (que inclui a indicação para qual a droga foi testada e possui evidência e reações adversas). Destaque-se: a Anvisa é órgão autárquico, independente, representa o Estado na regulação da economia, não se relacionando diretamente com a Política Nacional de Assistência Farmacêutica (PNAF) do SUS (ANVISA, 2012).

\footnotetext{
${ }^{6}$ Maria Sylvia Zanella Di Pietro traz como conceito moderno do Poder de Polícia o seguinte: “[...] é a atividade do Estado consistente em limitar o exercício dos direitos individuais em benefício do interesse público." (PIETRO, 2013, p.124).
} 
A formação da PNAF ofertada pelo SUS, será abordada em título próprio em razão deste elenco constituir um bem público, não sujeito ao valor de mercado. Assim, os medicamentos disponibilizados pelo SUS à população, para além do critério evidência e segurança, observam outras racionalidades, consideradas essenciais em políticas públicas.

Cumpre referir, ainda, que, em nome do acesso a medicamentos, a Lei n. ${ }^{\circ}$ 9787/99 acaba por definir "a Denominação Comum Brasileira como denominação do fármaco ou princípio farmacologicamente ativo aprovado pelo órgão responsável pela vigilância sanitária, e a Denominação Comum Internacional como denominação do fármaco ou princípio farmacologicamente ativo recomendado pela Organização Mundial da Saúde (COMESC, CNJ)". Dessa forma, pode-se concluir que a designação do medicamento se dá pelo seu princípio ativo, em nome da facilitação do acesso a quem necessitar deste insumo.

\section{2 "MEDICAMENTOS” E OS CRITÉRIOS PARA SEU FORNECIMENTO PELOS ENTES PÚBLICOS}

O fornecimento público de medicamentos é uma estratégia que compõe as diretrizes de ações do SUS, notadamente por meio da PNAF. Por meio da política, o poder público procura fornecer à população tratamentos/medicamentos reconhecidamente eficazes pela medicina ortodoxa, com o objetivo de promover o uso racional destes insumos. Tais tratamentos são disponibilizados administrativamente, bastando receituário e laudo médico que esclareça a necessidade do fármaco (BRASIL, 2006, res. n. ${ }^{\circ}$ 338).

É notório que a CF tenha atribuído ao Estado a competência para promover o direito a saúde, contudo, não isenta que esta seja uma prestação promovida por particulares, neste sentido se dá o entendimento da doutrinadora Gregori

A Constituição, ao tempo que assegurou ser a saúde direito de todos e responsabilidade do Estado, também autorizou a atuação da iniciativa privada na prestação de serviços de assistência à saúde (GREGORI, 2011, p.21).

No que tange a prestação ao direito à saúde sob a responsabilidade do Estado, ficou definido na normativa constante na Lei n. ${ }^{\circ} 8.080 / 90$ a competência para cada esfera de governo, conforme Corrallo ocorre da seguinte forma

Entre as competências do Gestor Federal, estabelecida na Legislação acima citada, chamamos a atenção para a formulação das políticas de saúde que devem ser pactuadas entre as três esferas de Governo. E para o financiamento das ações de assistência à saúde, promoção da saúde, prevenção de doenças, bem como das 
vigilâncias epidemiológica, sanitária e ambiental (CORRALLO, 2005, p.269).

No mesmo sentido referem às autoras Salazar e Grou, ao afirmar que tanto União, Estados e Municípios devem prover o direito posto em garantia pela Magna Carta, "a execução dos serviços e ações de saúde tornou-se dever de cada esfera de governo, de modo que cada uma delas, devendo agir juntas e de forma solidária, tem a competência administrativa definida pela Lei Orgânica da Saúde” (SALAZAR; GROU, 2009, p.45).

A competência administrativa é o critério objetivo criado para identificar a qual ente importará a prestação do direito à saúde. Esta lógica demonstra a organização multinível dentro do SUS e haverá uma espécie de divisão ao fornecimento de "Ações Primárias, de Média e Alta Complexidade, com integralidade" (CORRALLO, 2005, p.268).

Sendo assim, no que tange ao fornecimento de medicamentos como uma forma de garantia ao direito à saúde, há regulamentação por normativas internas, tais como portarias, que estabelecem critérios, como o grau de complexidade que vão definir a qual ente caberá o seu fornecimento. Nessa esteira argumentam as doutrinadoras Salazar e Grou, destacam:

A regionalização e hierarquização são pressupostos da descentralização de serviços, constituindo-se em conceitos e fórmulas organizativas do SUS, que supõe operá-lo com racionalidade de meios e fins. A hierarquização supõe três ou quatro níveis de complexidade de atenção integral à saúde, organizados cada qual com resolutividade própria (SALAZAR; GROU, 2009, p.46).

Conforme o grau de complexidade da medicação solicitada, a responsabilidade objetiva de seu fornecimento alternará a competência entre os entes federados. Pode-se resumir que a responsabilidade pela atenção primária ou básica, encontra-se sob a competência de gestão e disponibilidade dos municípios, a média complexidade sob a responsabilidade dos estados federados e a alta complexidade sob a responsabilidade de gestão e financiamento da União. Nesse contexto cabe referir a portaria n. ${ }^{\circ}$ 204/2007, do Ministério da Saúde, a qual dispõe a competência para fornecimento de medicamentos, frente a organização da RENAME (Relação Nacional de Medicamentos) pelos entes federados.

No que tange aos critérios de fornecimento de medicamentos, estes podem ser encontrados nas normas de assistência a saúde. A consolidação criada em razão da normativa SUS, vem contribuindo para uma melhor estruturação do sistema de saúde no Brasil, de forma a viabilizar a oferta da saúde pública enquanto um bem inesgotável. Salienta-se que houve uma descentralização dos serviços de saúde regulamentados pelo SUS, o que por as vez acarretou melhoras na prestação de serviços, conforme descreve Dobashi (presidente do CONASS). 
Nos últimos anos, com o processo de descentralização das ações e serviços de saúde, instituído pelas normativas do SUS, muitas ações e serviços que estavam sob a gestão e/ou execução do Estado foram transferidos para os municípios. Esse processo fez com que as Secretarias Estaduais de Saúde assumissem novas funções no sistema de saúde estadual, de coordenar o sistema de saúde de forma a garantir a integralidade do cuidado, por meio da implantação das Redes de Atenção à Saúde, com base nos princípios da escala, qualidade e do acesso (DOBASHI, 2011, p.15).

A ideia de transferência de atribuições dentro do sistema de saúde parte do pressuposto de melhorar o acesso da população às redes de atenção, sem perder de vista a estruturação técnica, que continua centralizada no Ministério da Saúde. Face a previsão constitucional do acesso universal, todo e qualquer cidadão brasileiro deverá ter seu direito de acesso ao SUS, que, nas interprataçoes pontuadas pelo CONASS:

O SUS deve ofertar, a todos os brasileiros, um conjunto de serviços sanitários e socialmente necessários, com base em protocolos clínicos e diretrizes terapêuticas e por meio de amplo movimento de discussão que envolva os gestores de saúde na Comissão Intergestores Tripartite e o Conselho Nacional de Saúde (CONASS, 2013).

Atualmente, o SUS passou a ser estruturado por meio de normas operacionais, as quais contam com uma elaboração conjunta das três esferas de governo e posteriormente formalizada pela criação de portarias. Ademais, a administração pública, por meio de sua discricionariedade confere a determinados órgãos o desenvolvimento das políticas públicas, nesta senda contribuem as doutrinadoras SALAZAR e GROU:

Neste sentido, a discricionariedade vem, por vezes, atrelada ás atividades que envolvem a prestação de serviços públicos de saúde, coordenadas pelos gestores de saúde, bem como aos atos administrativos da ANS, frutos da regulamentação e fiscalização dos planos de saúde. (SALAZAR, GROU, 2009, p.84).

Em razão do exposto, verifica-se a impossibilidade da concentração de atribuições gerenciais de políticas públicas, eis que esta concentração de poder, muitas vezes, acaba por possibilitar arbitrariedades por parte dos gestores, prejudicando a acessibilidade do sistema.

\section{FORNECIMENTO PÚBLICO DE MEDICAMENTOS E A REALIZAÇÃo DE PESQUISA EM HUMANOS}

A abordagem desta temática deseja sistematizar os principais aspectos que compõem o panorama da realização de pesquisa em humanos, com o objetivo de oferecer um parâmetro do "dever ser" social. A compilação deste "dever ser" orienta a adoção de posturas comprometidas com a própria promoção da vida e a responsabilidade social pelo outro, além 
de implicar na ação ética dos diversos órgãos que atuam em pesquisa: tanto da esfera pública, quanto da esfera privada.

\subsection{A JUDICIALIZAÇÃO DA SAÚDE E O FORNECIMENTO DE MEDICAMENTOS}

Nem sempre a esfera administrativa consegue suprir a grande demanda de fornecimento farmacológico e demais insumos relacionados à saúde e regulamentados pelas políticas públicas que compõe o SUS. Esta circunstância acaba por impulsionar o ingresso de pretensões na via judicial, para compelir os entes federados a realizar o fornecimentos destas prestações. Contudo, a proporção de ajuizamento de ações judiciais vem crescendo, bem como, as decisões do TJ/RS, por assumirem caráter repetitivo, vem relativizando os critérios e obrigações relacionadas ao direito e proteção da saúde.

Webber, ao enfrentar a temática, analisa a inoperância administrativa, afirmando que "Toda esta dificuldade de cumprimento das previsões legais sanitárias e sociais faz com que a população recorra ao Poder Judiciário, o que aumenta a complexidade social" (WEBBER, 2013). Dessa forma, o direito fundamental à saúde, vem sendo constantemente relativizado, a ponto de forçar um entendimento em que o direito individual ocupa um patamar absoluto, passando a ter maior relevância frente ao direito coletivo. Nesta senda, cumpre mencionar o entendimento de Kelbert, quando racionaliza a ideia de proteção dos bens que devam obter a tutela estatal, fazendo nos seguintes termos:

\footnotetext{
A necessária eleição de valores e bens a serem protegidos, as já referidas escolhas, engloba, ainda, outro aspecto, que diz respeito à relativização dos direitos protegidos. Conforme aduz Gustavo Amaral, "nada que custe dinheiro pode ser absoluto", de forma que alguns direitos ficarão sujeitos à possibilidade fática de sua efetivação por parte do ente estatal. (KELBERT apud AMARAL, 2011, p.67)
}

A judicialização de medicamentos experimentais, ou medicamentos que não obtiveram o seu reconhecimento pela Anvisa, perfaz uma lógica inversa a toda construção teórica de bem público, ao passo que se está priorizando o direito individual de modo a prejudicar o coletivo. Nesse sentido contribui Kelbert ao esclarecer a dimensão objetiva dos direitos fundamentais.

A dimensão objetiva dos direitos fundamentais pressupõe, ademais, a adoção de valores comunitários, ou seja, posições jurídicas que dizem respeito a toda sociedade. Por isso, uma decorrência dessa dimensão é a possibilidade de restringir direitos subjetivos individuais em prol de interesses comunitários [...] (KELBERT, 2011, p.54/55). 
Ocorre que este tipo de tratamento/medicamento é disponibilizado mediante pagamento de valores elevadíssimos, ou seja, o alto custo suportado pelos cofres públicos está adstrito a financiar tratamento de um indivíduo em específico, sem, contudo, ter certeza acerca da eficácia do mesmo. Esta é mais uma consequência negativa, em razão de onerar em demasiado os cofres públicos pela quando de sua judicialização. Em consonância com o exposto contribui o autor Kelbert,

A satisfação de um direito pleiteado pela via judicial poderá, muitas vezes, esgotar a capacidade orçamentária do ente estatal demandado, de forma que não será mais possível prestar outros direitos fundamentais, ou até aquele mesmo direito, em demanda diversa. Assim, conforme Galdino, geralmente os juízes não relevam os efeitos econômicos ao proferirem suas decisões, as quais ficam restritas ao problema jurídico, de modo que a questão econômica acaba sendo desconsiderada. (KELBERT apud GALDINO, p.68, 2011).

Percebe-se que toda coletividade fica prejudicada, haja vista que os recursos destinados a custear o tratamento de medicamentos com eficácia comprovada, não serão suficientes, pois estarão comprometidos em financiar uma incerteza. Para tanto, deverá existir uma estruturação por parte do Poder Judiciário a fim de suprir tal demanda e dirimir eventuais conflitos existentes, em razão de que os processos relativos a saúde "lato sensu" estão ultrapassando as previsibilidades de fornecimento e extrapolando a previsão orçamentária.

Se não bastasse as situações de prescrição de medicamentos alheios ao recorte institucional da política de saúde, para a realização de tratamentos, os profissionais da saúde tem ousado a prescrever medicamentos em caráter experimental, ou seja, passou-se a exigir a prestação do Estado, "lato sensu", de modo à judicializar medicamento que ainda não se pode aferir a sua eficácia, segurança e consequência. Neste sentido preceitua a doutrinadora Webber, ao definir o caráter experimental:

Dito de outra forma, deve se entender por experimentais os medicamentos cujas pesquisas (e portanto recomendações de uso indicados na bula) se deram em relação a uma determinada patologia, mas que muitas vezes são prescritos, e até alcançados pela via judicial, a outras enfermidades que não foram objeto da pesquisa. Por exemplo, quando um medicamento foi aprovado e testado para cura de câncer de estômago, mas passa a ser prescrito pelos médicos para tratamento de câncer de mama. (WBBER, 2013, p.55)

O caráter da experimentalidade tem seus riscos ignorados e acaba por ser inserido de várias formas para a realização de determinado tratamento. $\mathrm{O}$ caráter experimental do medicamento acaba por conferir um custo elevado para sua aquisição, sendo esta, mais uma 
consequência negativa, em razão de onerar os cofres públicos pela quando de sua judicialização. Em consonância com o exposto contribui o autor Kelbert, conforme trecho que segue

\begin{abstract}
A satisfação de um direito pleiteado pela via judicial poderá, muitas vezes, esgotar a capacidade orçamentária do ente estatal demandado, de forma que não será mais possível prestar outros direitos fundamentais, ou até aquele mesmo direito, em demanda diversa. Assim, conforme Galdino, geralmente os juízes não relevam os efeitos econômicos ao proferirem suas decisões, as quais ficam restritas ao problema jurídico, de modo que a questão econômica acaba sendo desconsiderada. (KELBERT apud GALDINO, 2011, p.68).
\end{abstract}

Face ao exposto, verifica-se a necessidade de uma analise criteriosa acerca dos gastos excessivos, provenientes, dos medicamentos postulados judicialmente. Ainda, em consonância com os argumentos apresentados, cabe referir que elevados gastos também acabam por ferir os princípios orçamentários que tem como escopo a proteção contra arbitrariedades no uso do dinheiro público. Neste sentido, vem corroborar as considerações das autoras Salazar e Grou,

\begin{abstract}
Ainda que a decisão acerca de quais despesas devam ser incluídas no orçamento público tenha natureza política, há certos limites constitucionais que devem ser respeitados para a elaboração do orçamento. Mais importante é atentar para o fato de que esta decisão não pode ser tomada com plena liberdade, mas sempre respeitando as prioridades e os limites constitucionais estabelecidos. (SALAZAR; GROU, 2009, p.91).
\end{abstract}

Embora o Supremo Tribunal Federal mantenha seu entendimento pacificado quanto a não obrigatoriedade do Estado em custear tratamento em caráter experimental, ainda há divergência de entendimento em relação ao Tribunal de Justiça do Estado do Rio Grande do Sul (WEBBER, 2013). Neste sentido, cabe suscitar a Recomendação de número 31 elaborada pelo Conselho Nacional de Justiça, o qual orienta, frente ao fornecimento de medicamento experimental, proceder da seguinte forma:

I. Recomendar aos Tribunais de Justiça dos Estados e aos Tribunais Regionais Federais que b.2) evitem autorizar fornecimento de medicamentos ainda não registrados na ANVISA, ou em fase experimental, ressalvadas as exceções expressamente previstas em lei

Enunciado 4- A determinação judicial de fornecimento de medicamentos deve observar a existência de registro na ANVISA (Aprovado por unanimidade) (CNJ, 2014).

O Sistema Jurídico prevê uma série de normativas que acabam por incompatibilizar o fornecimento de medicamento experimental sob o crivo do direito a saúde. Em alguns casos 
de deferimento deste tipo de tratamento, o que se observa é a total inobservância destas normativas ao permitir a concessão pelo Estado, deste tipo de medicamento, tendo como consequência, um financiamento público mascarado de pesquisas de medicamentos.

A conveniência para a indústria que está desenvolvendo o medicamento também está ligada ao fato de que o valor pago para se adquirir o fármaco será extremamente onerosa, pois não houve submissão à regulação do preço pelo Estado. Dessa forma, o Estado está a financiar as pesquisas, e após o depósito da patente ele também paga pelo invento, sendo que fica a critério do inventor fixar valores para a disponibilização do medicamento. Contudo, a única solução que se vislumbra para o Estado reduzir custos relativos aos medicamentos se dá por meio da quebra de patente, o que não configura uma decisão fácil, do ponto de vista econômico e das consequências que podem impactar pela ordem econômica internacional. Em consonância com o acima referido se dá as ponderações feitas pela doutrinadora Webber,

\begin{abstract}
A relevância alcançada pela legislação nesta temática dá-se pelo fato de que muitos dos medicamentos experimentais postulados atualmente prometem ser únicos. Entretanto, como aponta a professora da Harvard Medical School's, Marcia Angell, sabe-se que nem sempre isso é verdade, e isso só poderia ser apurado definitivamente por meio da quebra da patente do medicamento, já que só assim seria possível expor todos os seus componentes e principalmente a forma de fabricação do mesmo, que é o grande diferencial entre um medicamento e outro (WEBBER, apud ANGELL, 2013, p.117).
\end{abstract}

Desta feita, percebe-se que a quebra de patente possibilitaria que a indústria farmacêutica pública ou privada começasse a produzir determinado medicamento, imprimindo uma relação de concorrência, provocando baixa de preço e autonomia na fabricação do produto. Poderá, contudo, o amplo jogo de interesses econômicos que circundam a questão e que não a tornam simples para o administrador público.

É importante pontuar que a realização de pesquisas em seres humanos não possui uma legislação unificada e, no Brasil, é regulamentada por diversos órgãos: tanto por órgãos públicos como por entidade de classe médica. Nesta senda, a pesquisa optou por enfatizar as regulamentações públicas, oriundas de órgãos formados por técnicos do Estado quais sejam, o Conselho Nacional de Saúde (CNS), ANVISA, Comitê de Ética e Pesquisa (CEP), que se dedicam a delimitar e regulamentar as formas de realização de pesquisas em seres humanos, em que merecem destaque as Resoluções n. 1/88 e n. 196/96 do Conselho nacional de Saúde.

Esse conjunto normativo acaba por vetar quaisquer tipos de desajustes causados pela não observância das condições mínimas para uma vida digna do sujeito utilizado no experimento. 
Urge, portanto, a imposição de limites a moderna medicina, reconhecendo-se que o respeito ao ser humano, em todas as suas fases evolutivas (antes de nascer, o nascimento, no viver, no sofrer e no morrer) só é alcançado se estiver atento a dignidade humana. (RODRIGUES apud DINIZ, 2005, p.41).

Para Rodrigues, a pesquisa em seres humanos, deve preconizar a dignidade da pessoa humana, pois, a medida em que a pesquisa científica acaba por violar direitos fundamentais, ela deixa de cumprir com a sua finalidade. A apropriação desta discussão por todas as esferas públicas de poder se faz necessária, tendo em vista que tanto a norma, quando a operacionalização administrativa de suas determinações, e os julgados dos Tribunais necessitam afinar seus entendimentos para que não se promova o risco, em nome da cura.

\section{JUDICIALIZACÃO DA SAÚDE: O FORNECIMENTO DOS MEDICAMENTOS EXPERIMENTAIS E A RESPONSABILIDADE CIVIL DO ESTADO}

Nem sempre, a esfera administrativa consegue suprir a grande demanda de fornecimento farmacológico e demais insumos relacionados à saúde, o que acaba por impulsionar o ingresso na via judicial, a fim de obrigar os entes públicos ao seu fornecimento. Contudo, a proporção de ingressos com ações judiciais vem crescendo consideravelmente, bem como relativizando os critérios e obrigações relacionadas ao direito e proteção da saúde. Neste sentido, entende a doutrinadora WEBBER ao referir que "Toda esta dificuldade de cumprimento das previsões legais sanitárias e sociais faz com que a população recorra ao Poder Judiciário, o que aumenta a complexidade social.” (WEBBER, 2013).

A banalização do direito fundamental, acaba por colocar em evidência uma discussão descomprometida com os anseios de Estado, partindo-se da ideia de direito individual. Nesta senda, cumpre mencionar o entendimento de Kelbert, quando racionaliza a ideia de proteção dos bens que devam obter a tutela estatal, fazendo nos seguintes termos:

\subsection{A RESPONSABILIDADE CIVIL DO ESTADO FRENTE AO FORNECIMENTO DE MEDICAMENTOS EXPERIMENTAIS:}

A CF/88, em seu artigo 37 , parágrafo $6^{07}$ possibilita a interpretação da maioria dos doutrinadores no sentido de atribuir ao Estado a responsabilidade civil objetiva, sem, contudo

\footnotetext{
7 art. 37. A administração pública direta e indireta de qualquer dos poderes da União dos Estados do Distrito Federal e dos Municípios obedecerá aos princípios de legalidade, impessoalidade, moralidade, publicidade e eficiência e, também, ao seguinte [...].
} 
proceder análise de culpa. Nesta senda, Godoy descreve a responsabilidade civil como sendo uma forma de repar algum dano causado, porém, faz uma ressalva em que nem sempre a pessoa em que irá recair a culpa estará obriga a indenizar.

O papel central da responsabilidade civil é estabelecer meios e modos de ligar um fato danoso a um sujeito responsável, cujo patrimônio possa fazer frente ao prejuízo causado. É, por isso, uma maneira de se qualificar o fato danoso. A questão se poe na fixação das condições da relevância jurídica de um dano e das modalidades de imposição da respectiva obrigação de ressarcimento, e sem que o responsável seja necessariamente o autor, uma vez que o objetivo, não é, em si e por si, a descoberta da maioria do evento lesivo. (GODOY apud RODOTÁ, 2002, p.07)

Todo ato que cause dano ou alguma consequência negativa a outrem, deverá, por conseguinte existir uma reparação, uma contraprestação pela lesão sofrida. Essa atribuição de responsabilidade acima citada se dá de forma objetiva, sendo tal modalidade adotada, por maioria, como forma de responsabilizar o Estado pelos danos a que teria dado causa.

Nesta linha, cumpre mencionar os apontamentos dos doutrinadores GABURRI, BERALDO, et.al, no que tange a abrangência da responsabilização.

Como visto, é objetiva a responsabilidade do Estado pelos danos causados por seus agentes, em razão do serviço público (art.37 p 6, CF). Essa responsabilidade se funda na teoria do risco administrativo, segundo a qual, toda atividade administrativa gera riscos para as pessoas. Em princípio, essa atividade pressupõe um movimento do Estado no sentido de executar uma tarefa, ou seja, um conjunto de ações. (GABURRI; BERALDO; et.al., 2008, p.190)

Dessa forma, quando o Estado é obrigado, judicialmente, a fornecer medicamentos em caráter experimental, pela lógica acima exposta, seria objetivamente responsável por eventuais danos decorrentes desse tratamento. Contudo, não é obrigatoriedade do Estado o fornecimento deste tipo de medicamento, em razão de que o caráter experimental não permite a sua comercialização e, por óbvio, não é dispensado de forma voluntária pelo ente estatal.

De acordo com Gagliano e Filho, a culpa é um elemento essencial que irá determinar a quem recairá a responsabilidade de reparar eventual dano sofrido, senão vejamos:

A constatação de "culpa da vítima" fulmina a pretensão reparatória, não pela ausência de elemento subjetivo, mas sim por quebrar o nexo de causalidade necessário para o reconhecimento da reparabilidade do dano. (GAGLIANO; FILHO, 2009, p.195)

Parágrafo 6. As pessoas jurídicas de direito público e as de direito privado prestadoras de serviços responderão pelos danos que seus agentes, nessa qualidade, causarem a terceiros, assegurado o direito de regresso contra o responsável nos casos de dolo ou culpa. (BRASIL, 1988). 
Do argumento acima referido pode-se entender que, no caso de fornecimento público de medicamento experimental, o simples fato da voluntariedade de determinado indivíduo em ser submetido a este tipo de tratamento, ciente dos riscos decorrentes deste, não poderá o Estado ser responsabilizado por eventuais danos.

Ademais, o próprio caráter experimental, por si só, já exprime a ideia da existência de riscos quando da sua utilização, pois se não está aprovado, nem comprovado é porque não se pode mensurar as possibilidades tanto da capacidade de cura, quanto das consequências que possam vir a agravar o quadro de saúde. Igualmente, cumpre salientar que o simples fato de haver previsão constitucional tutelando o direito a saúde, não é suficientemente convincente para embasar uma concessão de medicamento experimental, em razão de que esta pauta-se exclusivamente no risco.

Não é dever do Estado, ainda mais de forma impositiva, que este forneça o risco, pois não se está observando o direito a saúde quando não se sabe precisar se a utilização de medicamentos experimentais resguardará a saúde do indivíduo, mas sim obter um efeito totalmente inverso expondo a saúde a riscos.

De acordo com o exposto, cumpre mencionar os ensinamentos dos doutrinadores Gaburri, Beraldo, et.al., conforme faz nos seguintes termos:

A adoção da responsabilidade objetiva do Estado não implica a adoção da teoria do risco integral, segundo o qual há sempre o dever de indenizar, ainda que o evento danoso tenha ocorrido por culpa da vítima, por caso fortuito ou força maior. (GABURRI; BERALDO; et.al., 2008, p.188)

A culpa da vítima pode ser analogicamente interpretada como a submissão voluntária de determinado indivíduo aos riscos do tratamento com medicamentos experimentais, o que por consequência não acarretaria uma responsabilidade objetiva do Estado.

\section{CONSIDERAÇOES FINAIS: A JURISPRUDÊNCIA DO TRIBUNAL DE JUSTIÇA DO RIO GRANDE DO SUL FRENTE AOS PEDIDOS DE FINANCIAMENTO DE MEDICAMENTOS EXPERIMENTAIS}

Em pesquisa realizada junto ao TJ/RS, fazendo uso das palavras chaves "fornecimento público medicamento experimental", considerando apenas o período de 2012, foi possível verificar que o entendimento das câmaras está dividido quanto à concessão de medicamentos experimentais. Dentre as câmaras estudadas, a vigésima segunda está dividida 
em deferir tratamentos/medicamentos de caráter experimental, eis que ocorreram dois deferimentos, sendo que em um deles foi desconstituído, inclusive, o caráter experimental alegado. Igualmente, cabe mencionar que a referida câmara em duas oportunidades teria negado o fornecimento de medicamentos experimentais

De forma diversa ocorre com a primeira câmara, eis que em duas situações nega a concessão de medicamento experimental e em apenas uma circunstância manifestou-se de forma favorável. As demais câmaras se encontram divididas, sendo as câmaras favoráveis a segunda, e a vigésima primeira, contudo, há uma resistência em conceder medicamentos experimentais na oitava câmara.

Os dados acima analisados, podem ser melhor compreendidos na tabela abaixo, em que há a indicação das câmaras, o número de deferimentos, indeferimentos e parcial deferimento da concessão de medicamentos experimentais, bem como o total de jurisprudências apuradas, referente ao ano de 2012, utilizando-se como filtro de pesquisa as palavras chave "fornecimento público" "medicamento experimental".

\begin{tabular}{|c|c|c|c|c|}
\hline Câmaras & $\begin{array}{c}\text { Deferimento de } \\
\text { medicamento } \\
\text { experimental }\end{array}$ & $\begin{array}{c}\text { Indeferimento de } \\
\text { medicamento } \\
\text { experimental }\end{array}$ & $\begin{array}{c}\text { Parcial deferimento } \\
\text { de medicamento } \\
\text { experimental }\end{array}$ & $\begin{array}{c}\text { Total de jurisprudências } \\
\text { apuradas }\end{array}$ \\
\hline Segunda & 01 & 02 & & 01 \\
\hline Vigésima Segunda & 02 & 02 & & 04 \\
\hline Primeira & 01 & 01 & & 03 \\
\hline Oitava & 01 & 05 & & 01 \\
\hline Vigésima Primeira & $\mathbf{0 5}$ & $\mathbf{0 5}$ & $\mathbf{1 0}$ \\
\hline Total: & & & & 01 \\
\hline
\end{tabular}

Fonte: Elaborado pelos autores conforme dados obtidos no TJ/RS, referente as decisões tomadas de janeiro a dezembro de 2012.

Pela sistematização realizada, pode-se perceber que o posicionamento adotado pelo TJ/RS encontra-se dividido, eis que metade dos julgados acaba por incutir ao Estado a obrigatoriedade de fornecimento de medicamento experimental e a outra parcela entende não ser dever do estado o custeio deste tipo de medicamento.

Ocorre que no caso de fornecimento público de medicamento experimental, quando não há aceitação pela Anvisa, que é o órgão encarregado para exercer o controle do mesmo, acaba por se judicializar o fornecimento, a fim de se definir a existência de possíveis direitos que possam vir a obrigar o fornecimento destes medicamentos pelo Estado, mesmo que tal discussão já tenha sido enfrentada (WEBBER, 2013). A autora ainda considera, 
Quando estas decisões prolatadas em primeiro grau passam a ser observadas pelo segundo grau ou Tribunais Superiores, dentro da hierarquia desta organização, o que se percebe é uma observação da segunda ordem, pois é uma observação da observação que já foi feita sobre o caso. Esta observação de segunda ordem vai permitir que se percebam pontos que ficaram nebulosos ao primeiro observador, criando um mecanismo que irá minimizar falhas e diminuir os riscos. (WEBBER, 2013, p. 145).

As decisões proferidas em sede de primeiro grau, em que já há uma análise acerca do direito à determinado tratamento, acabam por ser revistas pelo tribunal, em alguns casos com a reforma das decisões proferidas pelo juízo ad quo. Mas o que a referida doutrinadora ressalta é essa reanálise como forma de suprir questões que ainda não estão plenamente esclarecidas, no entanto, a autora ainda faz um alerta quanto ao reexame destas decisões por tribunais. Nesta linha, a autora questiona as decisões que contrariam, inclusive, órgãos próprios de controle, ao qual se atribui responsabilidade para atestar a viabilidade de fornecimento e comercialização de medicamentos.

A fundamentação do TJ/RS para conceder tratamentos mediante a utilização de medicamentos experimentais se dá basicamente pela argumentação constitucional do direito à vida, referindo que a necessidade comprovada deste medicamento, pela parte postulante, já legitima o seu deferimento. Exemplificativamente, cita-se o entendimento judicial proferido pela vigésima primeira câmara do TJ/RS, conforme segue:

AGRAVO. Possibilidade de prover monocraticamente recurso que ataca decisão proferida em manifesto confronto com jurisprudência dominante deste Tribunal e de Tribunais Superiores, nos termos do art. 557, $\$ 1^{\circ}-\mathrm{A}$, do Código de Processo Civil. Ratificação da decisão pelo Colegiado. ACESSO À SAÚDE. PROTEÇÃO SUFICIENTE. $O$ acesso à saúde é direito fundamental e as políticas públicas que o concretizam devem gerar proteção suficiente ao direito garantido, sendo passíveis de revisão judicial, sem que isso implique ofensa aos princípios da divisão de poderes, da reserva do possível ou da isonomia e impessoalidade. TRATAMENTO EXPERIMENTAL. CONFIGURAÇÃO. MEDICAMENTO NÃO APROVADO. ANVISA. Não tendo, o medicamento requerido, sido aprovado pela ANVISA, resta afastada a obrigação de seu fornecimento pelo Estado, por se tratar de tratamento experimental. AGRAVO DESPROVIDO. (Agravo No 70050656636, Vigésima Segunda Câmara Cível, Tribunal de Justiça do RS, Relator: Denise Oliveira Cezar, Julgado em 13/09/2012). (GRIFOS DAS AUTORAS)

Da referida decisão verifica-se, de forma muito clara, que o fundamento para embasar a obrigatoriedade do fornecimento de medicamento experimental é a garantia constitucional do direito a saúde, desconsiderando totalmente os riscos que permeiam o tratamento postulado.

De outra banda, a arguição utilizada pelo TJ/RS, a fim de desobrigar o Estado em fornecer medicamentos considerados experimentais se dá em virtude do próprio caráter 
experimental do medicamento, configurando uma impossibilidade de por sua propriedade farmacológica, motivo pelo qual não é passível de ser fornecido pelo ente público por não atentar aos critérios de controle impostos pela Anvisa.

É pertinente destacar o fundamento de decisões que negam tais pedidos, como a proferida pela vigésima segunda câmara do TJ/RS, em que acaba por desobrigar o ente federado em fornecer medicamentos experimentais:

DECISÃO MONOCRÁTICA. AGRAVO DE INSTRUMENTO. ACESSO À SAÚDE. PROTEÇÃO SUFICIENTE. O acesso à saúde é direito fundamental e as políticas públicas que o concretizam devem gerar proteção suficiente ao direito garantido, sendo passíveis de revisão judicial, sem que isso implique ofensa aos princípios da divisão de poderes, da reserva do possível ou da isonomia e impessoalidade. TRATAMENTO EXPERIMENTAL. CONFIGURAÇÃO. MEDICAMENTO NÃO APROVADO. ANVISA. Não tendo, o medicamento requerido, sido aprovado pela ANVISA, resta afastada a obrigação de seu fornecimento pelo Estado, por se tratar de tratamento experimental. AGRAVO DE INSTRUMENTO PROVIDO. DECISÃO MONOCRÁTICA. (Agravo de Instrumento $N^{\circ}$ 70049575806, Vigésima Segunda Câmara Cível, Tribunal de Justiça do RS, Relator: Denise Oliveira Cezar, Julgado em 19/07/2012). (GRIFOS DAS AUTORAS)

Comparando as decisões citadas, percebe-se uma certa incongruência do TJ/RS, haja vista que ambas as decisões foram proferidas pela vigésima segunda câmara cível, ou seja, mesmos julgadores para julgar a mesma causa de pedir. Verifica-se que no primeiro julgamento, a decisão é totalmente oposta ao segundo, porém, versam sobre o mesmo tema, a obrigatoriedade do Estado em fornecer medicamento experimental.

Ora, se no primeiro momento a concessão do medicamento experimental se deu sob o crivo do direito a saúde, no segundo momento há o reconhecimento da experimentalidade do fármaco que acaba por inviabilizar o seu fornecimento. Percebe-se que há o mesmo plano de fundo nos dois casos, contudo, argumentos diversos para solucionar o mesmo conflito.

\section{REFERÊNCIAS}

AGÊNCIA NACIONAL DE VIGILÂNCIA SANITÁRIA. Política de medicamentos. Disponível em:

<http://www.anvisa.gov.br/medicamentos/manual_politica_medicamentos.pdf >. Acesso em: 25 jun. 2014.

BAYMA, Fátima; KASZNAR, Istvan. Saúde e Previdência Social. Pearson Education, 2003.

BRASIL. Constituição. Brasília: Senado Federal, 1988. 
Lei 8.080, de 19 de setembro de 1990. Disponível em:

<http://www.planalto.gov.br/ccivil 03/leis/8080.htm>. Acesso em: 18 jun. 2014.

Lei 8.142, de dezembro de 1990. Disponível em: <http://www.planalto.gov.br/ccivil 03/leis/8142.htm>. Acesso em: 18 jun. 2014.

Lei 9.782, de 26 de janeiro de 1999. Disponível em:

<http://www.planalto.gov.br/ccivil_03/leis/19782.htm>. Acesso em: 18 jun. 2014.

Lei 9.787, de 10 de fevereiro de 1999. Disponível em:

<http://www.planalto.gov.br/ccivil_03/leis/19787.htm>. Acesso em: 18 jun. 2014.

Portaria 204, de 29 de janeiro de 2007, Ministério da Saúde. Disponível em:

<http://bvms.saude.gov.br/bvs/saudelegis/gm/2007/port0204_29_01_2007.html>. Acesso em: 18 jun. 2014.

Resolução 196, de 10 de outubro de 1996, Conselho Nacional de Saúde.

Disponível em:〈http://www.bioetica.ufrgs.br/res19696.htm\#cep>. Acesso em: 18 jun. 2014.

CONSELHO NACIONAL DE SECRETÁRIOS DE SAÚDE. Regulação em Saúde.

Disponível em: <http://www.conass.org.br/biblioteca〉. Acesso em: 04 jul. 2014.

CORRALlO, Giovani. Guia do Administrador Municipal. Nova Prova, 2004.

FEBRACE. Pesquisa com substâncias, equipamentos controlados ou perigosos (inclui atividade perigosas). Disponível em: $<\mathrm{http}: / /$ febrace.org.br/regras-deseguranca/equipamentos-perigosos/>. Acesso em 16 de out.2014.

FIGUEIREDO, Marina Filchtiner. Direito à Saúde. Jus Podivm, 2011.

GARCIA, L. P. et al. TD 1839-Dimensões do Acesso a Medicamentos no Brasil: Perfil e Desigualdade dos Gastos das Famílias, Segundo as Pesquisas de Orçamentos Familiares 2002-2003 e 2008-2009. Disponível em:

<http://www.ipea.gov.br/portal/images/stories/PDFs/TDs/td_1839.pdf>. Acesso em: 12 mai. 2014.

GAGLIANO, Pablo Stolze; FILHO, Rodolfo Pamplona. Novo Curso de Direito Civil Responsabilidade Civil, Saraiva, volume III,edição 2011.

GREGORI, Maria Stella. Planos de Saúde. Revista dos Tribunais, 2011.

HESSE, Konrad. A força normativa da Constituição: tradução de Gilmar Ferreira Mendes. Safe, 1991.

KARTZMAN IVAN. Curso prático de Direito Previdenciário. 8. ed. Juspodivm, 2011.

KELBERT, Fabiana Okchstein. Reserva do Possível e a efetividade dos direitos sociais no direito brasileiro. Livraria do advogado, 2011.

LEPARGNEUR, Hubert. Bioética, novo conceito. 2. ed. São Paulo: Loyola, 2004.

LINS, Litiane Cipriano Barbosa. Direitos socioambientais. Juruá, 2012. 
LUZ, Madel Therezinha. Ordem social, instituições e políticas de saúde no Brasil: testos reunidos. 1. ed. Rio de Janeiro: Cepesc, 2007.

MELLO, Celso Antônio Bandeira de. Eficácia das normas constitucionais e direitos sociais. Malheiros editores, 2009.

MORAES, de Alexandre. Direito Constitucional, 26. ed. Atlas 2010.

PETERSEN, Letícia Lassen. Políticas Sociais no SUS e a gestão da Assistência Farmacêutica na rede local/reegional: o caso da judicialização na $17^{a}$ Coordenadoria Regional de Saúde - RS. Tese de doutorado. Defesa 30/09/2014.

RODRIGUES, Hugo Thamir. Direito Constitucional \& Políticas Públicas. Porto Alegre: Imprensa Livre, 2005.

SALAZAR, Andrea Lazzarini; GROU, Karina Bozola. A Defesa da Saúde em Juízo. Verbatim, 2009.

WEBBER, da Silva Suelen. Decisão, Risco e Saúde. Juruá, 2013. 